\title{
Cross-scale modeling of surface temperature and tree seedling establishment in mountain landscapes
}

John R Dingman ${ }^{1,2^{*}}$, Lynn C Sweet ${ }^{1}$, lan McCullough ${ }^{3}$, Frank W Davis ${ }^{3}$, Alan Flint ${ }^{2}$, Janet Franklin ${ }^{4}$ and Lorraine E Flint ${ }^{2}$

\begin{abstract}
Introduction: Estimating surface temperature from above-ground field measurements is important for understanding the complex landscape patterns of plant seedling survival and establishment, processes which occur at heights of only several centimeters. Currently, future climate models predict temperature at $2 \mathrm{~m}$ above ground, leaving ground-surface microclimate not well characterized.

Methods: Using a network of field temperature sensors and climate models, a ground-surface temperature method was used to estimate microclimate variability of minimum and maximum temperature. Temperature lapse rates were derived from field temperature sensors and distributed across the landscape capturing differences in solar radiation and cold air drainages modeled at a 30-m spatial resolution.

Results: The surface temperature estimation method used for this analysis successfully estimated minimum surface temperatures on north-facing, south-facing, valley, and ridgeline topographic settings, and when compared to measured temperatures yielded an $R^{2}$ of $0.88,0.80,0.88$, and 0.80 , respectively. Maximum surface temperatures generally had slightly more spatial variability than minimum surface temperatures, resulting in $R^{2}$ values of 0.86 , $0.77,0.72$, and 0.79 for north-facing, south-facing, valley, and ridgeline topographic settings. Quasi-Poisson regressions predicting recruitment of Quercus kelloggii (black oak) seedlings from temperature variables were significantly improved using these estimates of surface temperature compared to air temperature modeled at $2 \mathrm{~m}$.

Conclusion: Predicting minimum and maximum ground-surface temperatures using a downscaled climate model coupled with temperature lapse rates estimated from field measurements provides a method for modeling temperature effects on plant recruitment. Such methods could be applied to improve projections of species' range shifts under climate change. Areas of complex topography can provide intricate microclimates that may allow species to redistribute locally as climate changes.
\end{abstract}

Keywords: Black oak; Climate change; Generalized linear models; Microclimate; Topography; Spatial scale; Surface temperature

\footnotetext{
* Correspondence: jdingman@usgs.gov

${ }^{1}$ Earth Research Institute, University of California Santa Barbara, Santa Barbara,

CA 93106, USA

¿U.S. Geological Survey, California Water Science Center, Sacramento, CA

95819, USA

Full list of author information is available at the end of the article
} 


\section{Introduction}

Microclimates at spatial scales of $1-1,000 \mathrm{~m}^{2}$ are the climates experienced by individual plants and thus are critical determinants of plant species distributions that must be considered when evaluating plant species vulnerability to climate change (Ashcroft 2010; Dobrowski 2011; Keppel et al. 2012; Rosenberg et al. 1983). The diversity of microclimates that occurs in mountainous terrain may allow a species to re-distribute locally under a changing climate, thereby buffering a species' exposure to regional climate change (Williams et al. 2008). Localized refugia can also provide stepping-stone connectivity for gene flow, dispersal and migration (Ackerly et al. 2010; Davis and Shaw 2001; Williams et al. 2008).

Although topographically related microclimate variation has been extensively documented and analyzed, spatially explicit modeling of mountain microclimates remains an active area of research (Ashcroft and Gollan 2012; Vanwalleghem and Meentemeyer 2009), as does research to better understand how microclimate variation is related to plant extinction risk under climate change (Ackerly et al. 2010; Keppel et al. 2012; Randin et al. 2009). One challenge lies in interpolating climate values across rugged topography from sparsely distributed weather stations that are usually located in level, open sites (Ashcroft and Gollan 2012). A second challenge is estimating the microclimate near the ground surface from weather station measurements typically collected $2 \mathrm{~m}$ or more above the ground surface. Many organisms, including plant seedlings, live on or near the ground surface where temperature variation can be much greater than the variation at $2 \mathrm{~m}$ (Kearney and Porter 2009; Rosenberg et al. 1983). A third challenge is that for most plant species we lack knowledge of which aspects of microclimate are most important in controlling initial establishment, growth or reproduction.

In this study we are concerned with modeling finescale variation of air temperatures close to the ground surface and relating that variation to tree seedling recruitment in mountain landscapes. The study is part of a larger multi-year project integrating climate model downscaling, microclimate measurement and modeling, experimental studies of tree seedling recruitment, and spatially explicit plant population models to link microscale ecological processes to macro-scale species range dynamics under climate change (Davis and Sweet 2012). Our study region is in California, where hot and dry summer conditions associated with the Mediterranean climate regime place strong abiotic controls on tree seedling establishment and sapling survival, and may factor importantly into population dynamics and species distributions (Gomez-Aparicio et al. 2008; Zavala et al. 2000). Seedlings must establish an adequate root system to survive a long summer drought (Mahall et al. 2009), and surface temperatures near the ground can be lethally hot for small-stemmed seedlings (Kolb and Robberecht 1996). For light-loving tree species, recruitment of new individuals occurs in clearings created by wildfires or other disturbances, and the microclimates in such clearings can be especially extreme and under strong topographic influence compared to forested sites (Chen et al. 1999; Ma et al. 2010). Thus, microclimate may influence seedling abundance and distribution differently or more so than is the case for adult trees (Collins and Carson 2004; Tsujino and Yumoto 2007), depending on the scale of study (Stohlgren et al. 1998), and this topic is therefore particularly relevant to the study of plant species recruitment. Studies of seedling response to abiotic and biotic conditions will be key to predicting range shifts, as populations may shift via seedling establishment into new areas with climate change (Lenoir et al. 2009).

We describe and test an approach for modeling landscape variation in an important microclimate variablemaximum daily near-ground surface temperatures-based on air temperature profiles measured in the field, 30-m grids of modeled monthly solar insolation, and coarse (4-km) spatial grids of air temperatures $2 \mathrm{~m}$ above the surface. We then relate average maximum daily temperatures to seedling recruitment (germination + survival to end-of-summer) data from experimental field trials to produce a seedling thermal niche model for California black oak (Quercus kelloggii). We apply our near-ground surface temperature model to map that seedling niche across a study landscape in the southern Sierra Nevada. Our results illustrate both the potential to model fine-scale near-ground surface temperature variation and the importance of doing so in order to describe spatial variation in seedling establishment across mountain landscapes.

\section{Methods}

Study area

We are measuring microclimate and tree seedling recruitment in foothill and montane sites in two neighboring ecoregions and seed zones, the southern Sierra Nevada and the western Tehachapi Mountains in California (Figure 1). Our Sierran sites comprise the San Joaquin Experimental Range $\left(37^{\circ} 5^{\prime} \mathrm{N}, 119^{\circ} 43^{\prime} \mathrm{W}, 210-520 \mathrm{~m}\right.$ elevation, www.fs.fed.us/psw/ef/san_joaquin) and Teakettle Experimental Forest $\left(36^{\circ} 58^{\prime} \mathrm{N}, 119^{\circ} 1^{\prime} \mathrm{W}, 2,000-2,800 \mathrm{~m}\right.$, www.fs.fed.us/psw/ef/teakettle). Our Tehachapi sites comprise landscapes at low $\left(34^{\circ} 59^{\prime} \mathrm{N}, 118^{\circ} 43^{\prime} \mathrm{W}, 750-930 \mathrm{~m}\right)$ and high $\left(34^{\circ} 58^{\prime} \mathrm{N}, 118^{\circ} 35^{\prime} \mathrm{W}, 1,600-1,700 \mathrm{~m}\right)$ elevations on the Tejon Ranch.

We tested our microclimate downscaling approach at Teakettle Experimental Forest. The average annual precipitation here is $110 \mathrm{~cm}$ and falls predominantly in the winter months as snow (North et al. 2002). Over the period 1971-2000, the mean daily minimum temperature 


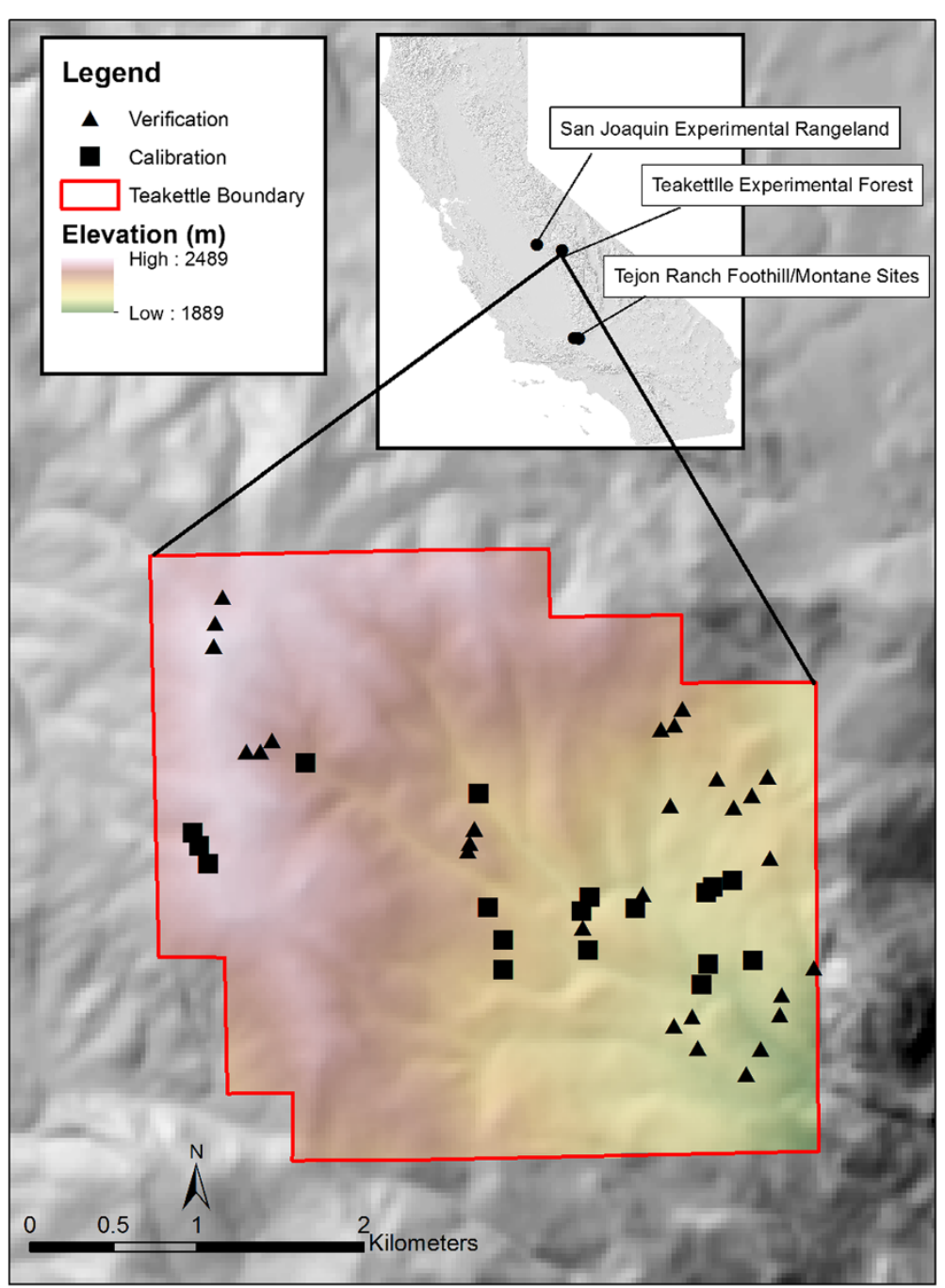

Figure 1 Location map of project study sites in California, USA. Temperature data recorded across the Teakettle landscape were partitioned into two categories, modeled data and verified data. The modeled data sensors were used to calculate lapse rates needed for estimating surface temperature from 17 individual locations. Verified data were collected at 29 separate locations to estimate the accuracy of the landscape surface temperature model.

during January was $-3.6^{\circ} \mathrm{C}$ and the mean maximum daily temperature in August was $24^{\circ} \mathrm{C}$ (PRISM Climate Group 2012). The forest primarily consists of mixed-conifer species, with occasional black oak (Quercus kelloggii). Native conifer species at lower elevations include white fir (Abies concolor), sugar pine (Pinus lambertiana), incense cedar (Calocedrus decurrens), and Jeffrey pine (Pinus jeffreyi). Species such as red fir (Abies magnifica), lodgepole pine (Pinus contorta), and western white pine (Pinus monticola) increase in abundance at higher elevations on the site (North et al. 2002).

\section{Microclimate measurements}

At the Teakettle Experimental Forest we set up 17 individual temperature sampling locations for calibration and 29 temperature sampling locations for verification using
$\mathrm{HOBO}^{\circledR}$ (Onset, www.onsetcomp.com) data loggers to record temperature every 10 minutes beginning in August 2011. A dense array of 21 temperature sensors at $0.05 \mathrm{~m}$ above ground was installed in a circular area $20 \mathrm{~m}$ in radius centered on each $5 \times 5 \mathrm{~m}$ common garden (described below; associated plant species planted together in another environment). We deliberately sampled at high density to ensure accurate estimation of mean near-ground surface temperatures at these sites for calibration or validation of 30-m downscaled climate models. At each of six garden sites, the sensor in the center was used for calibration and the surrounding 20 sensors were used for validation by averaging them into a monthly value of minimum and maximum temperature. An additional 29 temperature recording locations were allocated across the landscape (hereafter, "landscape" sensors or locations) to capture 
temperature variation related to hillslope orientation and valley drainages (Figure 1). Of these 29 landscape sensors, 12 were used for calibration and the remaining 17 were used for validation. At each experimental garden and at several landscape locations, a stack of sensors recorded temperature at three vertical distances above the ground surface: 4, 2, and $0.05 \mathrm{~m}$ or 3, 1, and $0.05 \mathrm{~m}$. One of these two vertical arrangements of temperature sensors was used to record temperature at each site and estimate the lapse rate by adjusting the z-term, the height of recorded temperature. We shielded the thermocouples (sensor used to measure temperature) at 0.05 and $1 \mathrm{~m}$ from direct sunlight by suspending them inside inverted white styrene funnels $10 \mathrm{~cm}$ in diameter. Thermocouples at 2 and $4 \mathrm{~m}$ heights were suspended in Onset RS3 solar radiation shields. The data loggers were tested in a climatecontrolled cold storage room prior to deployment. Quality assurance and quality control methods from the National Oceanic and Atmospheric Administration (NOAA) Meteorological Assimilation Data Ingest System (MADIS) were used to filter out data that may have resulted from sensor drift or spiking (http://madis.noaa.gov/madis_qc. html). Where there were inadequate data for the month due to sensor failure, data from that sensor were not used.

Spatial autocorrelation among the temperature sampling locations was evaluated for dispersion and clustering patterns with respect to distance using Ripley's $K$ function with 99 permutations (Bailey and Gatrell 1995; Boots and Getis 1988). To determine the degree of autocorrelation occurring at Teakettle among recorded temperatures, the residuals of the near-ground surface temperature (Campbell) predicted from measured nearground surface temperature (validation data) were calculated. Moran's I was used to test if these residuals were autocorrelated across Teakettle, that is, if they were spatially clustered or statistically considered random, suggesting the sampling locations could be treated as independent observations (Getis and Ord 1992).

Modeling the air temperature profile near the ground surface We modeled the vertical temperature profile near the ground using the equation from Campbell and Norman (1998, p. 20), which is based on the theory of turbulent heat transport and assumes a uniform surface with steadystate conditions. Equation 1 from Campbell and Norman (1998) was used to estimate coefficients needed to fit the temperature profile at each of the 17 temperature recording locations with a vertical mast containing the three temperature sensors (as described above):

$$
T(z)=T_{0}-\frac{H}{0.4 \rho c_{p} u^{*}} \ln \frac{z-d}{z_{\mathrm{H}}}
$$

where $T(z)$ is the estimated temperature at height $z$ above the soil surface, $T_{0}$ is the surface temperature, $H$ is the sensible heat flux from the surface to the air, $\rho c_{p}$ is the volumetric specific heat of air $\left(1,200 \mathrm{~J} \mathrm{~m}^{-3} \mathrm{C}^{-1}\right.$ at $20^{\circ} \mathrm{C}$ and sea level), and 0.4 is von Karman's constant, $u^{*}$ is the frictional velocity, $d \approx 0.6 h$, where $h$ is the vegetation height, and $z_{\mathrm{H}} \approx 0.02 h$, a roughness parameter for heat transfer.

We applied this model using the vertical temperature records to solve a system of three equations containing three unknown variables: ground-surface temperature $\left(T_{O}\right)$, lapse rate $\left[A=H /\left(0.4 p c_{p} u^{*}\right)\right]$, and vegetation height $(h)$. First, $h$ was estimated across a range of values ranging from 0 to $10 \mathrm{~cm}$ with an interval of 1 $\mathrm{mm}$, and for each value of $h$ we then solved for $A$ and $T_{0}$, providing different estimates in temperature for each $h$ value. The best estimates of $h, A$, and $T_{0}$ were selected using a third temperature measurement by matching the predicted temperature with the observed temperature at the highest measurement height.

\section{Downscaling regional climate grids}

We applied Equation 1 to model monthly averages of minimum and maximum temperature aggregated from daily measurements near the ground surface using $4-\mathrm{km}$ resolution temperature grids obtained from the PRISM Climate Group, Oregon State University (http://prism.oregonstate.edu). The 4-km grids were downscaled to $30 \mathrm{~m}$ using a two-stage downscaling process, first downscaling to $800 \mathrm{~m}$ and then from $800 \mathrm{~m}$ to $30 \mathrm{~m}$ using digital elevation models (DEM) with $4-\mathrm{km}, 800-\mathrm{m}$, and $30-\mathrm{m}$ spatial resolutions. The downscaling method, which is described in detail by Flint and Flint (2012), fits local climate gradients using multiple regression models to predict temperature or rainfall from elevation along bi-directional (north to south and east to west) gradients and weights the regression estimate for new locations using inverse-distance-squared weighting of values from the coarser grid.

The PRISM Climate Group produces 4-km monthly grids of average minimum and maximum temperature by interpolating weather station temperature measurements using a weighted regression approach based on location, elevation, coastal proximity, topographic orientation, and other terrain effects (Daly et al. 2008). Given that the temperature measurements are typically collected at $2 \mathrm{~m}$ above the surface, we treat our downscaled PRISM temperature grids as modeled temperatures at a height of $2 \mathrm{~m}$.

To derive 30-m grids of monthly minimum and maximum temperatures at the ground surface, we applied our estimated lapse rates for 17 locations using the following relationship, a rearrangement and simplification of Equation 1: 


$$
T_{0}=T_{\mathrm{PRISM}}+A \ln \frac{z-d}{z_{\mathrm{H}}}
$$

where $T_{0}$ is the monthly estimate for either minimum or maximum ground surface temperature, $T_{\mathrm{PRISM}}$ is the estimated monthly minimum or maximum temperature at $z=$ $2 \mathrm{~m}$ above ground obtained from the 30-m downscaled PRISM grid for that month, $A$ is the monthly lapse rate averaged across 18 measurement locations, and $z, d$, and $z_{\mathrm{H}}$ are as defined above (Equation 1).

To estimate monthly minimum and maximum temperatures near the ground surface at a height of $0.05 \mathrm{~m}$, we applied the following equation, a rearrangement of Equation 2:

$$
T(0.05)=T_{0}-A \ln \frac{z-d}{z_{\mathrm{H}}}
$$

where $T(0.05)$ is the monthly estimate for either minimum or maximum surface temperature at $z=0.05 \mathrm{~m}$, $T_{0}$ is as determined from Equation 2 , and $A, d$, and $z_{\mathrm{H}}$ are as defined above (Equations 1 and 2).

We only considered snow-free months (September and October 2011 and May through September 2012), given that temperature sensors buried under snow recorded a constant temperature of approximately $0^{\circ} \mathrm{C}$. We would have also included October 2012, but we had incomplete field temperature data for this month. Equations 2 and 3 assume that monthly lapse rates are uniform across the landscape. We expected that lapse rates could vary systematically on more open southfacing slopes and ridges than in canyons and northfacing slopes due to differences in surface thermal properties, local airflow patterns, daytime heating from solar radiation, and other systematic terrain effects. To refine our lapse rate estimates for modeling maximum monthly temperatures, we adjusted local lapse rates based on least-squares linear regression of lapse rates as a function of solar radiation. Modeled solar radiation was used to estimate only maximum near-ground surface temperatures and not minimum temperatures due to the variability in solar heating among aspects during the day from the sun's thermal energy. Grids of monthly clearsky solar radiation were calculated as described in Flint and Childs (1987). Their solar model accounts for both direct and diffuse radiation and is based on solar geometry, local slope angle and azimuth, and shading effects of surrounding ridges. Average daily radiation load was calculated by summing instantaneous radiation for 360 integration points per day, with $10^{\circ}$ resolution of the horizon for modeling shading from surrounding ridges.

Our monthly near-ground surface temperature models were verified using independent surface temperature measurements from 29 sampling locations. A leastsquares regression analysis was used to compare how well the predicted model temperatures match those of the independent observed measured temperatures.

\section{Recruitment of Quercus kelloggii seedlings}

We are studying the relationship of tree recruitment to microclimate at 24 common gardens (6 gardens at each of 4 sites). We located gardens in clearings to mimic post-disturbance site conditions in two south-facing, two north-facing, and two valley topographic settings longer than $40 \mathrm{~m}$ across. Gardens were planted in the autumn (2011) prior to snowfall: in October at Teakettle and the Tehachapi high-elevation site, in November at the Tehachapi low-elevation site, and in December at the San Joaquin site. Jute netting was used to stabilize bare soil surfaces created during garden installation in order to reduce erosion and possible displacement of seeds.

Quercus kelloggii (black oak) seed was collected from the USDA Forest Service seed zone 533 containing Teakettle Experimental Forest and from zone 570 in the Tehachapi Mountains. Acorns were collected by hand in October 2011 from at least ten wild trees in each zone. Seeds were gathered directly from the trees and the ground, excluding seeds that were partially predated, damaged, or appeared desiccated and those that could not be detached from the cupule easily. After collection, the seeds were placed into plastic containers with perlite to prevent molding. Seeds collected at different locations within a zone were combined and mixed to ensure a consistent population-level sample when selected for planting in the gardens. Seed was stored in Ziploc ${ }^{\circledR}$ bags of perlite in groups of 50 , first at $15^{\circ} \mathrm{C}$ and then changed to $4^{\circ} \mathrm{C}$ after 1 week (to suppress germination and arrest mold development). Bags of seed were monitored for mold and decay until planted in the common gardens.

In late October 2011, 25 Q. kelloggii plots were planted in a randomized complete block design in each of two replicate mono-specific plots $(0.5 \times 1 \mathrm{~m})$ as part of the larger common garden experiment. Within the plots, seeds were planted in a grid design, $10 \mathrm{~cm}$ apart (50 seeds per plot), just beneath the soil surface. Measurements of height and basal diameter were made in June and August for all emerged seedlings. Recruitment was calculated as the number of seedlings alive in August.

The relationships between seedling recruitment (number surviving in August 2012) and temperature variables were fitted using quasi-Poisson Generalized Linear Models ( $\mathrm{R}$ Core Team 2012). A quasi-Poisson model was used because the mean was greater than the variance in our recruitment data. Several temperature variables were tested to investigate which monthly maximum temperatures were most correlated with seedling recruitment, and results are shown for July average maximum temperature because this time period may include lethal temperatures and occurred just prior to the mid-August assessment of 
seedling recruitment. To evaluate the difference in significance of coefficients and variance explained from modeling temperature regimes near the ground versus at $2 \mathrm{~m}$, we estimated and compared two simple GLMs based on observed maximum temperatures at 0.05 and $2 \mathrm{~m}$ above the ground surface. We fit a second-order polynomial for the temperature predictor because it captures the hypothesized unimodal shape of the temperature response curve over the range of measured temperatures in the garden experiment (Austin 2002). The dismo library (Hijmans et al. 2012) was used to apply the resulting GLMs to $30-\mathrm{m}$ resolution grids of modeled maximum near-ground surface temperatures at 0.05 and $2 \mathrm{~m}$ height. Maps created using ArcScene (ESRI, www.esri.com) show these distribution models of predicted Q. kelloggii seedling recruitment.

\section{Results}

\section{Observed minimum and maximum temperatures}

Peak maximum temperatures of $47^{\circ} \mathrm{C}$ were recorded on July 9 th near the soil surface on south-facing slopes at Teakettle (Figure 2). Summer daytime maximum temperatures were typically $8-12^{\circ} \mathrm{C}$ higher at $0.05 \mathrm{~m}$ than at $2 \mathrm{~m}$ at the same location (Figure 2). Maximum daily temperatures at $0.05 \mathrm{~m}$ were $\sim 2^{\circ} \mathrm{C}$ warmer on southfacing slopes and in valleys compared to those on north-facing slopes (Figure 2). At $2 \mathrm{~m}$, maximum temperatures were relatively spatially uniform across the landscape (Figure 2).
Site-wide estimates of near-surface lapse rates for monthly maximum temperature averaged $1.20^{\circ} \mathrm{C}$, but estimates varied considerably by month, ranging from 0.10 to $1.36^{\circ} \mathrm{C}$. Steepest lapse rates were generally recorded during summer months. Lapse rates also varied considerably among sites and at the same site between years (Table 1).

Compared to maximum daily temperatures, minimum daily temperatures during the summer were much more uniform across the landscape and the lapse rates were closer to zero (Figure 3, Table 2). Mid-summer minimum temperatures ranged from 5.8 to $15.6^{\circ} \mathrm{C}$ and were not significantly different at 0.05 vs. $2 \mathrm{~m}$ above the soil surface for north-facing slopes or valleys. South-facing slopes were $0.75-1.5^{\circ} \mathrm{C}$ warmer at $2 \mathrm{~m}$ above the ground surface compared to elsewhere on the landscape, often being the warmest areas of minimum temperature (Figure 3). Sitewide average lapse rate for monthly minimum temperature for all 7 months was approximately $0.15^{\circ} \mathrm{C}$, ranging from 0.12 to $0.16^{\circ} \mathrm{C}$. Lapse rates did not vary systematically with respect to topography, but lapse rates at individual locations tended to be consistently higher or consistently lower than site-wide averages.

\section{Modeled landscape variation of near-ground surface temperature}

Downscaled 30-m grids of predicted monthly minimum temperatures at $2 \mathrm{~m}$ above the ground surface were strongly correlated with observed minimum near-ground surface temperatures (Table 3). Similarly, estimates of

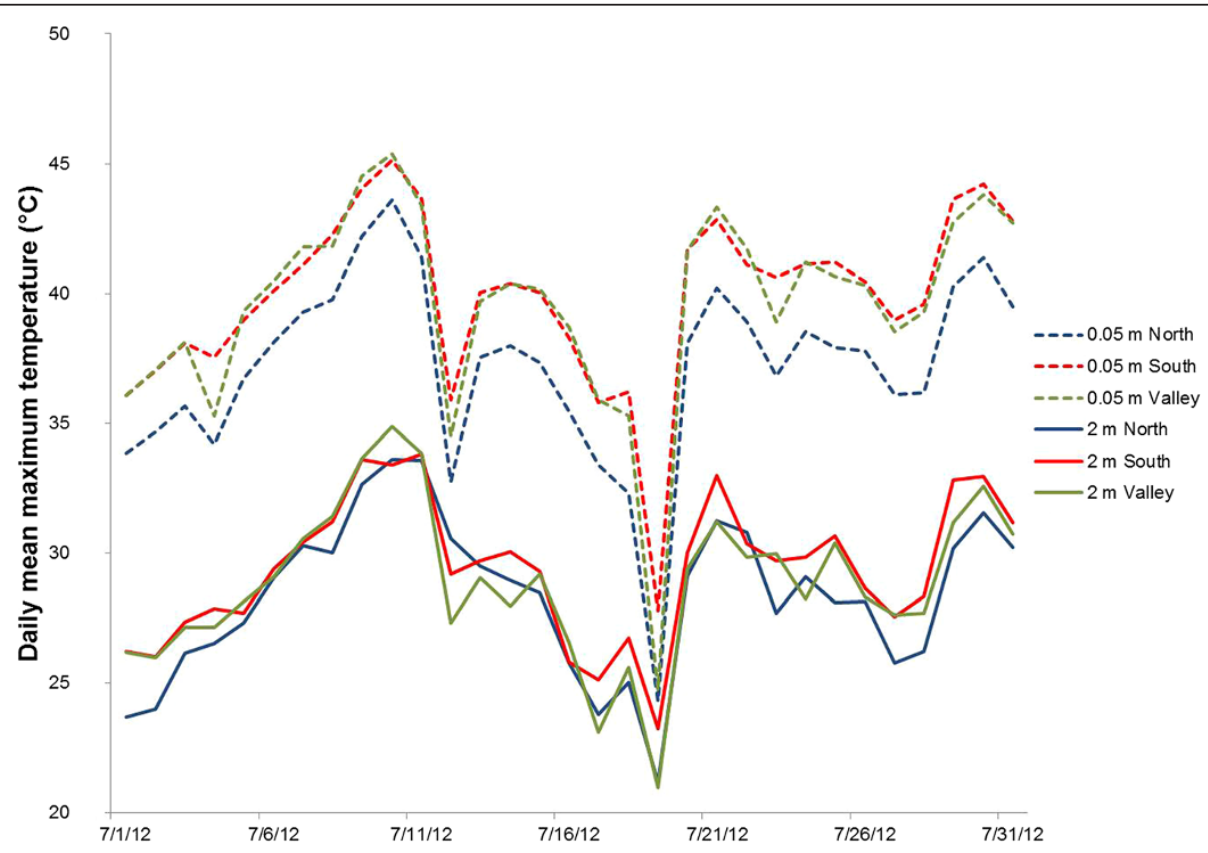

Figure 2 Representative daily mean maximum temperatures for the Teakettle Watershed study site during July 2012. Daily mean maximum temperatures at $0.05 \mathrm{~m}$ (dashed lines) and $2 \mathrm{~m}$ (solid lines) are from three experimental gardens including north-facing (blue), southwest-facing (red) and valley (green) locations. 
Table 1 Estimated monthly averages of near-ground surface lapse rates ( $A$ in Equations 2 and 3 ; $\left.^{\circ} \mathrm{C}\right)$ used to model the vertical profile of maximum monthly temperatures at the Teakettle Experimental Watershed for September-October 2011 and May-September 2012

\begin{tabular}{|c|c|c|c|c|c|c|c|c|c|}
\hline Location & Topographic position & Sep-11 & Oct-11 & May-12 & Jun-12 & Jul-12 & Aug-12 & Sep-12 & Average \\
\hline N1 & North slope & - & - & - & - & 1.59 & 1.53 & 1.01 & - \\
\hline N2 & North slope & 1.20 & 0.76 & 1.14 & 1.38 & 1.50 & 1.66 & 1.74 & 1.34 \\
\hline N3 & North slope & 0.56 & 0.09 & 1.22 & 1.38 & 1.24 & 1.39 & 0.72 & 0.94 \\
\hline N4 & North slope & 1.80 & 1.11 & - & - & - & - & - & - \\
\hline N5 & North slope & 0.32 & 0.12 & - & 0.34 & - & - & - & - \\
\hline $\mathrm{N}$-average & North slope & 0.97 & 0.52 & 1.18 & 1.03 & 1.44 & 1.52 & 1.16 & 1.12 \\
\hline R1 & Ridge & 0.12 & 0.31 & - & - & - & - & - & 0.21 \\
\hline S1 & South slope & - & - & - & - & 1.87 & 1.66 & 1.98 & - \\
\hline S2 & South slope & 1.10 & 0.78 & 0.86 & 1.33 & 1.20 & 1.16 & 1.03 & 1.07 \\
\hline S3 & South slope & 0.60 & 0.17 & 1.76 & 1.82 & - & - & 1.45 & - \\
\hline S5 & South slope & 1.31 & 1.62 & - & - & - & - & - & - \\
\hline S-average & South slope & 0.97 & 0.52 & 1.18 & 1.03 & 1.44 & 1.52 & 1.16 & 1.12 \\
\hline V1 & Valley & - & - & - & - & 1.44 & 1.32 & 1.36 & - \\
\hline V2 & Valley & 0.69 & 0.02 & 1.18 & 1.61 & 1.43 & 1.41 & 1.34 & 1.10 \\
\hline V3 & Valley & 0.76 & 0.31 & 0.99 & 1.45 & 1.63 & 1.17 & 1.63 & 1.14 \\
\hline V4 & Valley & 1.21 & 0.89 & 1.76 & 2.15 & - & - & - & - \\
\hline V5 & Valley & 1.17 & 0.79 & 1.67 & 1.85 & - & - & - & - \\
\hline V6 & Valley & - & - & - & - & 2.46 & 2.33 & 2.07 & 2.29 \\
\hline V-average & Valley & 0.96 & 0.50 & 1.40 & 1.76 & 1.74 & 1.56 & 1.60 & 1.36 \\
\hline
\end{tabular}

Dash marks represent months with incomplete data for that sensor.

minimum daily near-ground surface temperatures were strongly correlated $\left(\mathrm{R}^{2}=0.80\right)$ with observed variation across all topographic settings (Table 3 ). Model predictive capacity was greatest for valleys $\left(\mathrm{R}^{2}=0.88\right.$ ) (Table 3 ). In general, observed minimum temperatures recorded in the field were found to be colder than modeled near-ground surface minimum temperatures by approximately $0.83^{\circ} \mathrm{C}$.

Estimated monthly maximum temperature lapse rates were positively correlated with monthly solar radiation, with steepest lapse rates observed at locations receiving the highest insolation $\left(R^{2}=0.34\right.$, Figure 4$)$. Downscaled $30-\mathrm{m}$ grids of PRISM monthly maximum temperatures at $2 \mathrm{~m}$ above the ground surface were, as expected, not well correlated with, and systematically cooler than, recorded maximum temperatures at $0.05 \mathrm{~m}$ height $\left(\mathrm{R}^{2}=0.61\right.$, Table 3). The relationship improved after applying Equations 2 and 3 to the downscaled PRISM grids using site-wide monthly estimates of $A\left(\mathrm{R}^{2}=0.73\right)$ and was slightly further improved by adjusting lapse rate based on monthly insolation $\left(R^{2}=0.75\right)$. Overall, the model was best at predicting temperature along north-facing slopes $\left(\mathrm{R}^{2}=0.86\right.$, Table 3$)$. Accuracy in terms of mean absolute error between modeled and observed temperatures was $1.63^{\circ} \mathrm{C}$ for minimum and $3.57^{\circ} \mathrm{C}$ for maximum temperatures
(Table 4). The progression of modeled monthly maximum surface temperatures for September-October 2011 and May-September 2012 is shown for the Teakettle Watershed study (Figure 5); hottest surface conditions across the landscape are predicted to have occurred in August and on south-facing slopes.

While evaluating spatial autocorrelation among the temperature sampling locations using Ripley's $K$ function, we found the sampled pattern of temperature to be spatially random, falling within a 95\% confidence envelope. The observed $K$ function with respect to distance was neither clustered nor dispersed. The residuals, calculated as the difference between the predicted and measured near-ground surface temperatures, were not spatially clustered in any of the seven months. Moran's $I$ for model residuals ranged from -1.02 for October 2011 to 0.05 in September 2011. P-values fell between 0.22 and 0.88 , suggesting that residuals calculated for each month were neither significantly dispersed nor clustered.

\section{Observed and modeled seedling recruitment}

Maximum July temperature at $0.05 \mathrm{~m}$ (near the ground surface) explained more variance in recruitment than temperature measured at $2 \mathrm{~m}$ above the ground surface 


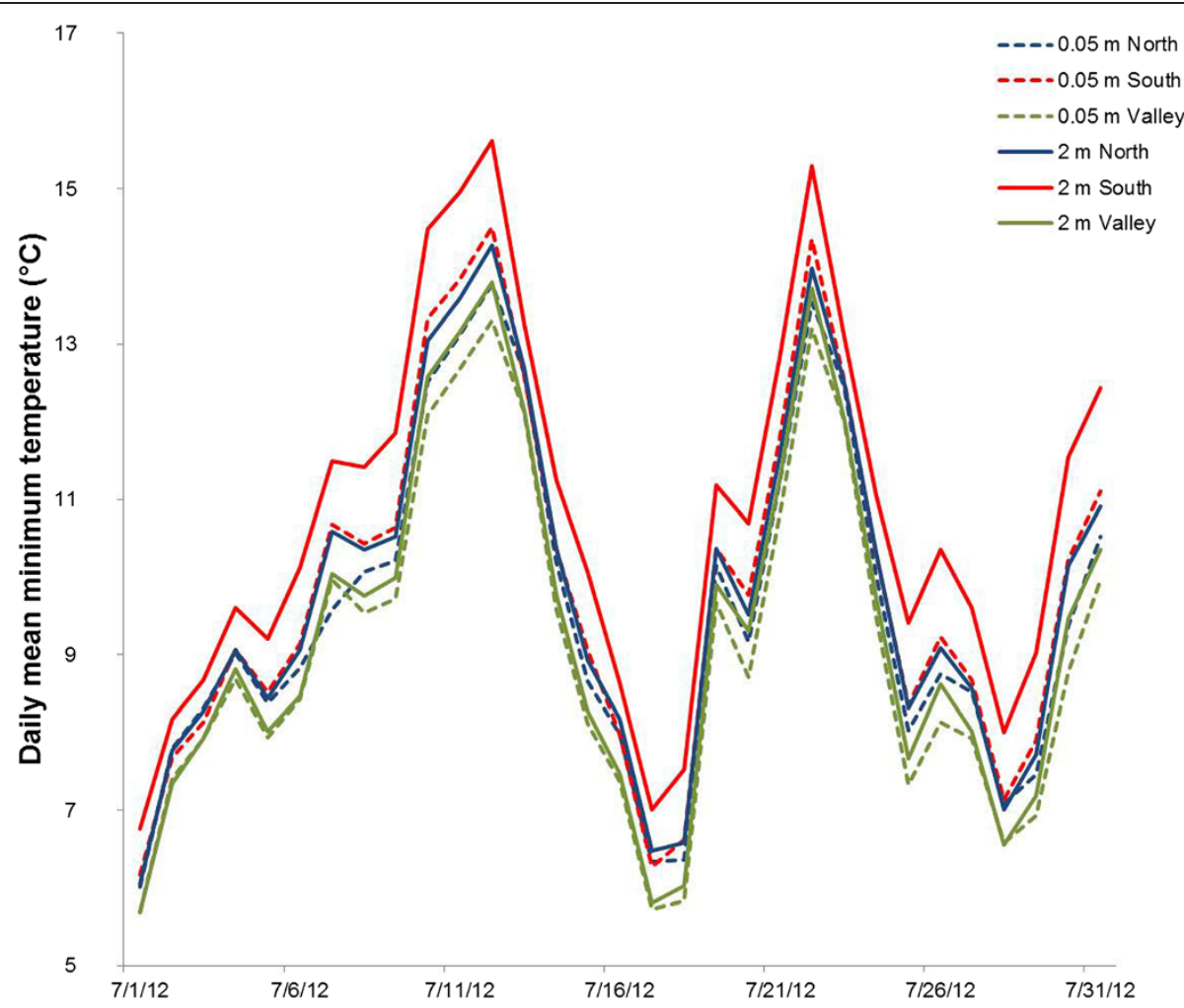

Figure 3 Representative daily mean minimum temperatures for the Teakettle Watershed study site during July 2012. Daily mean minimum temperatures at $0.05 \mathrm{~m}$ (dashed lines) and $2 \mathrm{~m}$ (solid lines) are from three experimental gardens including north-facing (blue), southwest-facing (red) and valley (green) locations.

(adjusted $\mathrm{R}^{2}$ of 0.63 versus 0.41 respectively; Table 5 ). Further, the estimated parameters were larger in magnitude and were significant (at a significance level of alpha $=$ 0.05 ) for the model based on $0.05 \mathrm{~m}$ temperature measurements, versus $2 \mathrm{~m}$ (Table 5). The response curve estimated for the temperature variable measured near the ground also more completely characterized the optimum and upper and lower limits of tolerance than the curve estimated from $2 \mathrm{~m}$ data (Figure 6).

A predictive map of seedling recruitment as a function of July maximum temperature, generated by applying the quasi-Poisson regression model to the $2-\mathrm{m}$ gridded temperature dataset, shows a very smooth recruitment surface with moderately high predicted recruitment even in the upper elevation limits of the study area (Figure 7a). The map generated using the model of recruitment based on the $0.05 \mathrm{~m}$ temperature data shows greater topographic variation in modeled black oak seedling recruitment and generally lower recruitment probability, especially at the upper elevations of Teakettle, and higher predicted recruitment in the lower elevation areas surrounding the study area (Figure $7 \mathrm{~b})$.

\section{Discussion}

Evaluation of landscape-scale near-ground surface temperature estimation

Modeling and estimating temperatures near the ground surface has been important in understanding microrefugia and assessing species vulnerability to rising global temperatures (Fridley 2009). Other studies have deployed a dense grid of temperature sensors to record fine-scale variability across the landscape among different topographic settings capturing the influence of nearby streams, soil moisture, solar insolation, and vegetation cover (Ashcroft 2010). Maps of surface temperatures have then been produced based on statistical or geostatistical modeling (Vanwalleghem and Meentemeyer 2009; Ashcroft and Gollan 2012). We have used a different approach that combines spatial downscaling of monthly PRISM data to produce $30-\mathrm{m}$ grids of air temperatures at $2 \mathrm{~m}$, followed by calculation of near-ground surface temperatures using the observed temperature lapse rates and modeled solar insolation. The Campbell and Norman model used to estimate near-ground surface temperature is based on a comprehensive model of surface energy balance often used in climate forecasting to 
Table 2 Estimated monthly averages of near-ground surface lapse rates $\left({ }^{\circ} \mathrm{C}\right)$ used to model the vertical profile of minimum monthly temperatures at the Teakettle Experimental Watershed for September-October 2011 and MaySeptember 2012

\begin{tabular}{|c|c|c|c|c|c|c|c|c|c|}
\hline Location & Topographic position & Sep-11 & Oct-11 & May-12 & Jun-12 & Jul-12 & Aug-12 & Sep-12 & Average \\
\hline $\mathrm{N1}$ & North slope & - & - & - & - & -0.04 & -0.05 & -0.06 & - \\
\hline N2 & North slope & -0.11 & -0.19 & -0.08 & -0.08 & -0.11 & -0.12 & -0.12 & -0.12 \\
\hline N3 & North slope & -0.07 & -0.06 & -0.19 & -0.02 & -0.04 & -0.04 & -0.04 & -0.07 \\
\hline N4 & North slope & -0.16 & -0.12 & - & - & - & - & - & - \\
\hline N5 & North slope & -0.64 & -0.58 & - & -0.29 & - & - & - & - \\
\hline $\mathrm{N}$-average & North slope & -0.25 & -0.24 & -0.14 & -0.13 & -0.06 & -0.07 & -0.07 & -0.14 \\
\hline $\mathrm{R} 1$ & Ridge & -0.12 & -0.12 & - & - & - & - & - & -0.12 \\
\hline S1 & South slope & - & - & - & - & -0.29 & -0.27 & -0.32 & - \\
\hline $\mathrm{S} 2$ & South slope & -0.13 & -0.09 & -0.14 & -0.11 & -0.12 & -0.01 & -0.15 & -0.11 \\
\hline S3 & South slope & -0.03 & -0.02 & -0.21 & -0.04 & - & - & 0.00 & - \\
\hline S4 & South slope & -0.25 & -0.23 & -0.18 & -0.19 & - & - & - & - \\
\hline S5 & South slope & -0.13 & -0.37 & - & - & - & - & - & - \\
\hline S-average & South slope & -0.25 & -0.24 & -0.14 & -0.13 & -0.06 & -0.07 & -0.07 & -0.14 \\
\hline V1 & Valley & - & - & - & - & -0.24 & -0.28 & -0.27 & - \\
\hline V2 & Valley & -0.16 & -0.16 & -0.10 & -0.12 & -0.16 & -0.17 & -0.17 & -0.15 \\
\hline V3 & Valley & -0.09 & -0.07 & -0.05 & -0.07 & -0.08 & -0.08 & -0.08 & -0.07 \\
\hline V4 & Valley & -0.16 & -0.07 & -0.11 & -0.10 & - & - & - & - \\
\hline V5 & Valley & - & - & -0.48 & -0.63 & - & - & - & - \\
\hline V6 & Valley & - & - & - & - & -0.11 & -0.13 & -0.11 & -0.12 \\
\hline V-average & Valley & -0.14 & -0.10 & -0.18 & -0.23 & -0.15 & -0.17 & -0.16 & -0.16 \\
\hline
\end{tabular}

Dash marks represent months with incomplete data for that sensor.

estimate surface heat fluxes (e.g., Holtslag and Van Ulden 1983).

Our findings demonstrate that landscape-scale estimation of minimum and maximum near-ground surface temperature is feasible through the combination of downscaled conventional climate datasets, vertical temperature profile interpolation methods, and field calibration data. Accuracy in terms of mean absolute error between modeled and observed temperatures was generally better for minimum than maximum temperatures, likely due to greater fine-scale variability in maximum temperature lapse rates. Lapse rates calculated from field temperature sensors varied more, spatially and temporally, for monthly maximum near-ground surface temperature than for minimum near-ground surface temperature. Maximum near-ground surface temperature is highly heterogeneous and varies not only by topographic aspect and slope steepness, but is further complicated by soil and ground cover albedo, which absorbs or reflects solar radiation. Furthermore, gaps in canopy cover attenuate

Table 3 Squared correlation coefficients $\left(R^{2}\right)$ between PRISM and observed (HOBO) minimum and maximum temperatures $\left({ }^{\circ} \mathrm{C}\right)$ and between observed and estimated minimum and maximum surface temperatures using various lapse rate estimation methods

\begin{tabular}{|c|c|c|c|c|c|}
\hline Analysis & All aspects & North & South & Valley & Ridgeline \\
\hline \multicolumn{6}{|l|}{ Minimum temperature } \\
\hline PRISM vs. HOBO & 0.82 & 0.80 & 0.75 & 0.88 & 0.86 \\
\hline HOBO vs. average lapse rate & 0.80 & 0.79 & 0.75 & 0.88 & 0.86 \\
\hline \multicolumn{6}{|l|}{ Maximum temperature } \\
\hline PRISM vs. HOBO & 0.60 & 0.72 & 0.59 & 0.55 & 0.75 \\
\hline HOBO vs. average lapse rate & 0.68 & 0.82 & 0.76 & 0.62 & 0.72 \\
\hline HOBO vs. regressed solar lapse rate & 0.69 & 0.81 & 0.76 & 0.59 & 0.77 \\
\hline
\end{tabular}

n: north: 18 , south: 30 , valley: 21 , ridgeline: 18 , total: 87 .

Analysis points consisted of paired comparisons between monthly temperature datasets. 


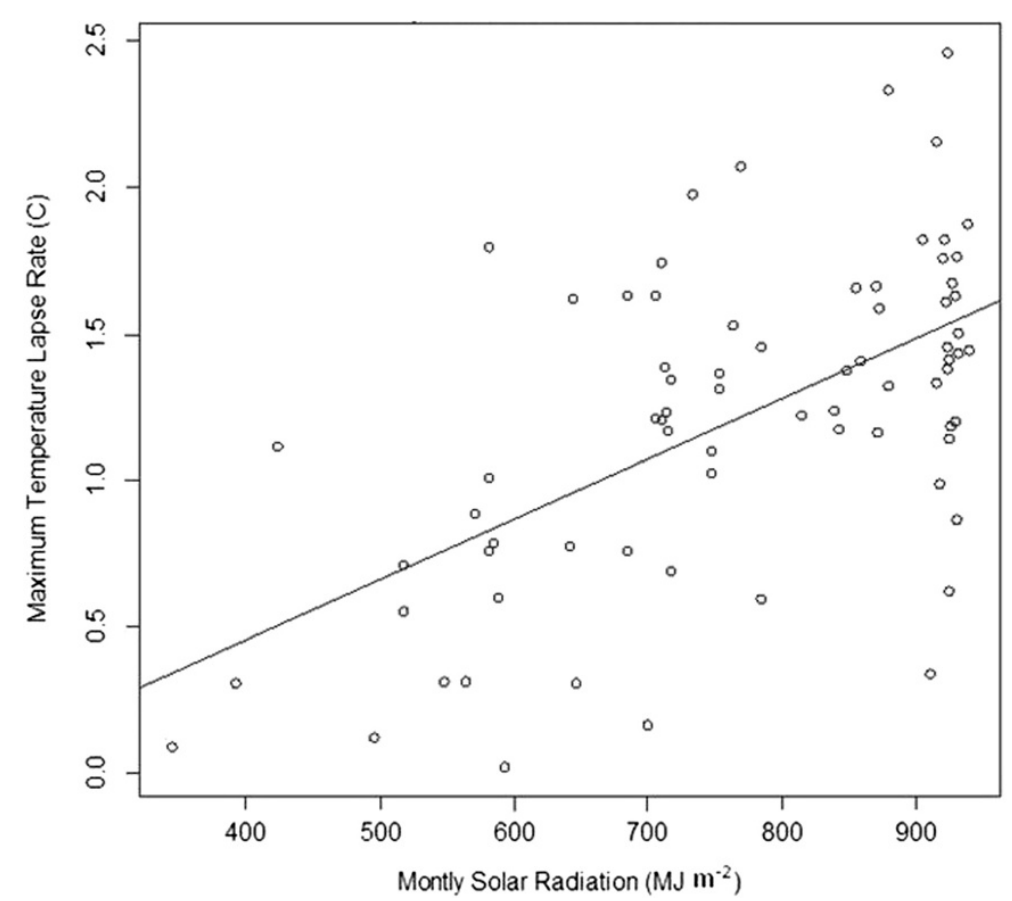

Figure 4 Scatterplot of integrated monthly solar radiation $\left(\mathrm{MJ} \mathrm{m}^{-2}\right)$ vs. estimated lapse rate $\left({ }^{\circ} \mathrm{C}\right)$ for the near-ground surface profile of maximum daily temperatures. Linear regression equation $(y=0.002 x+0.367)$ with an $R^{2}=0.34$.

solar radiation before it reaches the ground causing differences in surface temperatures (Fridley 2009).

Model accuracy was highest on north-facing slopes. Although Dobrowski (2011) reported that aspect has little direct effect on minimum temperature, the increased solar radiation on south-facing slopes and ridgelines may interact with the dry soil conditions during summer months at Teakettle and promote stronger divergence from the regional temperature patterns characterized in large-scale climate datasets. The ridgeline regions at Teakettle make up a relatively small area compared to other sampled landscapes. Consequently, we had only one temperature recording location that captured ridgeline variability, making it more difficult to estimate near-ground surface temperatures along mountain ridges. Locally, north-facing slopes experience the smallest amount of solar radiation and the most canopy shading and, therefore, the narrowest fluctuations in temperature and lapse rates compared to the other sites. To better understand patterns of near-ground surface temperatures in mountainous regions we plan to add temperature recording stations that capture the vertical temperature profile at our other three other research sites, San Joaquin Experimental Range and Tehachapi low and high elevation landscapes. With these additional temperature recording sites, near-ground surface temperature models will support models of tree seedling recruitment in all project study areas, allowing us to better link topographically influenced micro-scale climate to macro-scale tree species range dynamics.

Table 4 Mean absolute error between PRISM and observed (HOBO) minimum and maximum temperatures ( ${ }^{\circ} \mathrm{C}$ ) and between observed and estimated minimum and maximum surface temperatures using various lapse rate estimation methods

\begin{tabular}{|c|c|c|c|c|c|}
\hline Analysis & All aspects & North & South & Valley & Ridgeline \\
\hline \multicolumn{6}{|l|}{ Minimum temperature } \\
\hline PRISM vs. HOBO & 1.59 & 1.58 & 1.44 & 1.24 & 2.24 \\
\hline HOBO vs. average lapse rate & 1.63 & 1.58 & 1.66 & 1.20 & 2.15 \\
\hline \multicolumn{6}{|l|}{ Maximum temperature } \\
\hline PRISM vs. HOBO & 9.92 & 7.48 & 10.47 & 9.61 & 11.80 \\
\hline HOBO vs. average lapse rate & 3.82 & 1.92 & 4.22 & 4.55 & 4.18 \\
\hline HOBO vs. regressed solar lapse rate & 3.57 & 1.92 & 3.62 & 4.71 & 3.79 \\
\hline
\end{tabular}

n: north: 18 , south: 30 , valley: 21 , ridgeline: 18 , total: 87 .

Analysis points consisted of paired comparisons between monthly temperature datasets. 

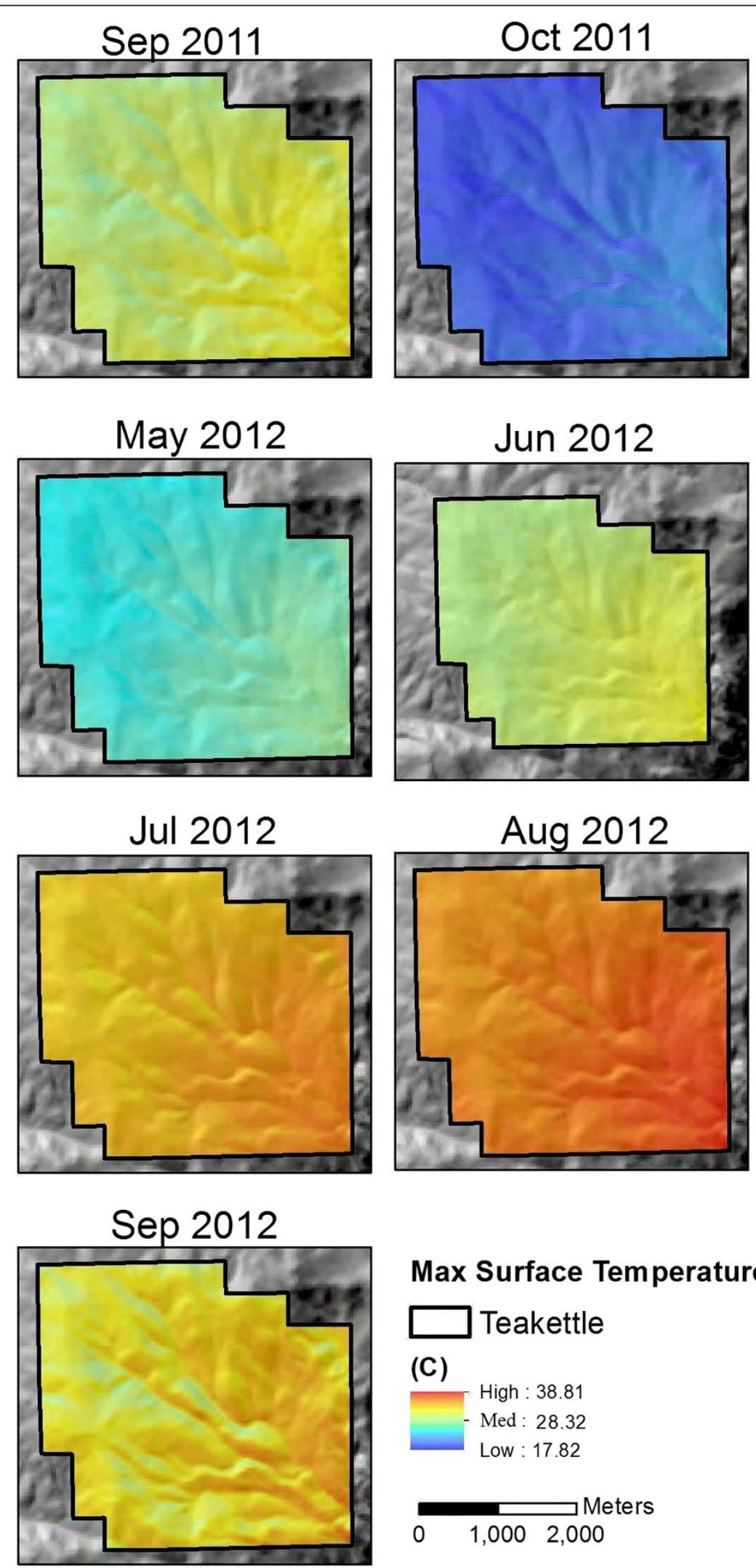

\section{Max Surface Temperature}

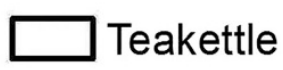

(C)

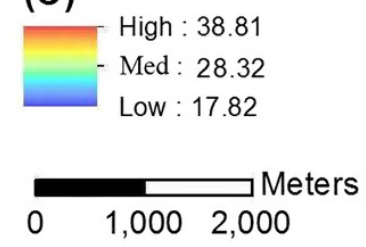


Numerous studies have shown that including topographically based variables to account for cold air pooling, particularly those pertaining to water drainage and accumulation, improves estimation of temperature across the landscape (Lookingbill and Urban 2003; Lundquist et al. 2008; Dobrowski et al. 2009). Bigg et al. (2012) demonstrated that cold air pooling occurs throughout the year and is strongest and most frequent during summer and autumn in a study of the Peak District of central England. Notably, these cold air pooling events occurred at small scales, approximately $0.5-1 \mathrm{~km}$. In mountainous landscapes such as Teakettle, knowledge of small-scale patterns of cold air pooling could enable spatial predictions of climate refugia, which in this case would act as small sanctuaries decoupled from regional climate regimes for more cold-adapted species (Daly et al. 2010).

\section{Implications for species distribution modeling}

Landscape-scale estimation of near-ground surface temperatures makes possible microclimate modeling for plant seedlings or other species that experience climate at the ground surface. Plant seedlings must endure the surface level microclimate to become established individuals, meaning exposure to considerably warmer temperatures than those that are found at just a couple of meters above ground. Conventional climate datasets (e.g., PRISM) based on mean maximum temperatures measured at $2 \mathrm{~m}$ insufficiently represent the magnitude and variability of maximum temperatures at the ground surface. Furthermore, hot and cold temperature spikes may be lethal to certain species during critical life stages, but inadequately described within mean temperature datasets (Bateman et al. 2012; Reyer et al. 2013) regardless of temperature measurement height. Use of such datasets to predict distributions of species that experience ground surface microclimate could produce misleading results and misinform management strategies.

In the case of the black oak, for a seedling to survive the first growing season, several ecophysiological requirements must be met: acorns require thermal stratification (Burns et al. 1990); adequate moisture and temperatures must occur in the springtime for germination and emergence from the soil; enough nutrients and light energy must be available for growth beyond seed stores; and seedlings must survive possible late frosts or lethally hot surface temperatures during a long summer drought period. As a direct (e.g., thermal energy for chemical processes; lethal stem temperatures) or indirect (proxy for soil drydown) driver, it stands to reason that July maximum temperature would be an important predictive variable in oak recruitment. Although black oak has been studied in silvicultural settings (e.g., McDonald 1978), and foundational research by Griffin (1971) documented life history traits such as seed set and germination and differences in seedling emergence in foothill woodland microhabitats, the literature on black oak seedling ecology is not extensive (Tyler et al. 2006). Our results are consistent with prior findings, including those of Standiford et al. (1991), that solar radiation (which covaries with slope-aspect and temperature) is a significant factor in explaining the probability of seedling regeneration.

Our experiment underscores the importance of nearground surface temperatures for black oak seedling recruitment (Figure 7). Species distribution models (Franklin 2010) generally map suitable habitat for adult individuals of species, but it cannot be assumed that juveniles establish and survive under the same conditions (Ibanez et al. 2007; Jackson et al. 2009; McLaughlin and Zavaleta 2012), nor that the spatial distribution of suitable microhabitats for juveniles across landscapes is the same as that of adults.

\section{Conclusions}

Our study demonstrates the importance of including ground surface microclimate in predicting future species distributions in response to climate change. Montane landscapes contain considerable microclimatic variability that could provide important refugia for species threatened by climate change. Refugia are often identified as areas of overlapping suitable habitat between existing and projected future species distributions or sometimes as areas outside current suitable habitat that are expected to

Table 5 Summary of results of simple quasi-Poisson GLMs of number of Quercus kelloggii seedlings recruited (response variable) as a quadratic function of July average maximum temperature measured at two heights (temp. height)

\begin{tabular}{ccccccc}
\hline Temp. height & Parm poly1 & $\boldsymbol{P}$ (poly1) & Parm poly 2 & $\boldsymbol{P}$ (poly2) & Adj R $^{\mathbf{2}}$ & Dispers parm \\
\hline $0.05 \mathrm{~m}$ & 5.431 & 0.021 & -0.070 & 0.018 & 0.63 & 3.90 \\
$2 \mathrm{~m}$ & 2.661 & 0.359 & -0.053 & 0.313 & 0.42 & 7.63 \\
\hline
\end{tabular}

Parm poly1 is the estimated parameter for the linear term of the temperature variable, and parm poly2 is the estimated parameter for the squared term. $P()$ are the probabilities that those terms are not significantly different from zero. Dispers parm is the dispersal parameter of the quasi-Poisson model. 

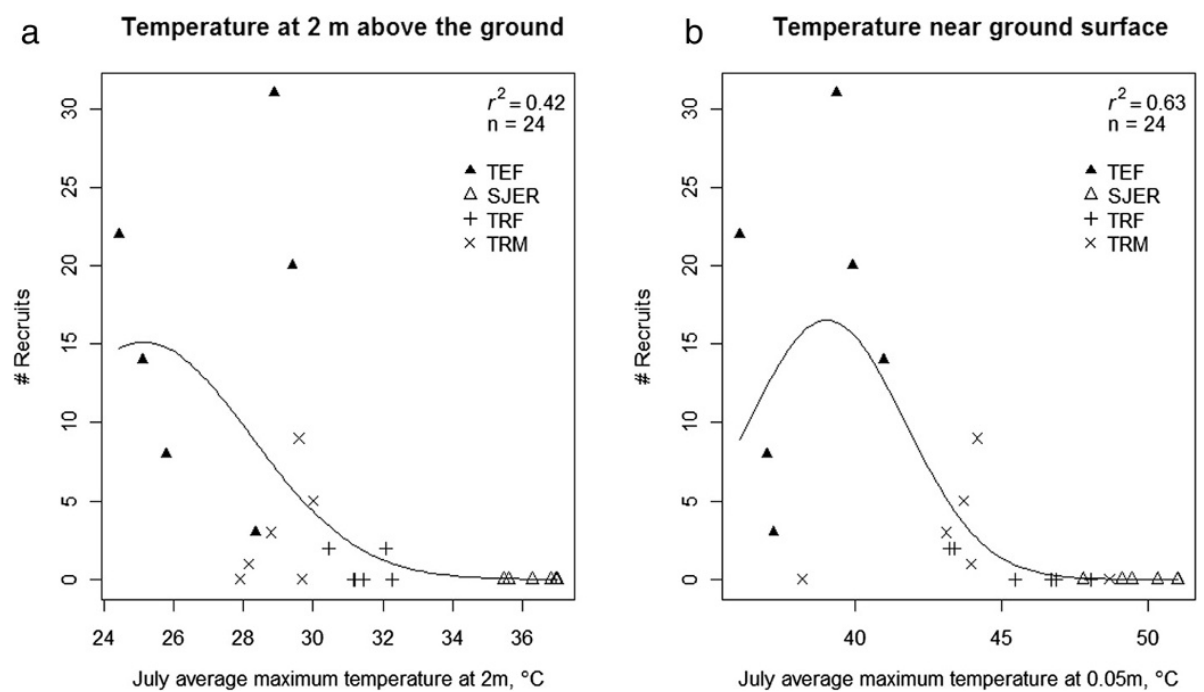

Figure 6 Recruitment of $Q$. kelloggii seedlings (number of seeds surviving in August out of 50 planted) in experimental gardens as predicted by measured average July daily maximum temperature at all study sites (a) $2 \mathrm{~m}$ and (b) $0.05 \mathrm{~m}$ above the soil surface. Fitted lines are from 2nd-order polynomial quasi-Poisson GLMs based on number of recruits as the response variable. Abbreviations: TEF, Teakettle Experimental Forest; SJER, San Joaquin Experimental Range; TRF, Tejon Ranch Foothill site; TRM, Tejon Ranch Montane site.

become suitable in the future (e.g., Franklin et al. 2013). The concept of climate change refugia has drawn attention in recent discussions of conservation responses to climate change (Ashcroft 2010; Keppel et al. 2012; Keppel and Wardell-Johnson 2012). Yet despite this attention, the role of climate-species relationships during early life stages in identifying and conserving potential refugia has received insufficient consideration due to the common assumption that climate-species relationships are static throughout the lives of individuals (McLaughlin and Zavaleta 2012 is an exception). Therefore, conservation of plant species under climate change could depend on our ability to model the responses of species to ground-surface microclimate. This study represents a step forward in both modeling ground-surface microclimate at relatively fine scales and understanding how this fine-scale variability may influence plant seedling survival and govern landscape and regional patterns of future species distributions.
Climate models, such as PRISM, that are based on temperature measured at $2 \mathrm{~m}$ above the ground surface require estimated lapse rates if they are to be used to model ground-surface temperature. Temperatures near the ground surface tend to be more extreme and heterogeneous than above-ground temperatures due to the differences in albedo, soil moisture, and vegetation density near the ground. Having a network of temperature sensors that capture the vertical temperature profile and are distributed among different topographic settings allows us to better understand microclimate variability with respect to near-ground surface temperature.

Modeling tree species recruitment as a function of near-ground surface temperature provided insight on how a species might establish across the landscape with respect to fine-scale microclimate variability. Modeling maximum temperatures at the ground surface, a potentially harsh environment that acts as a fine filter through which tree seedlings must pass to establish successfully,

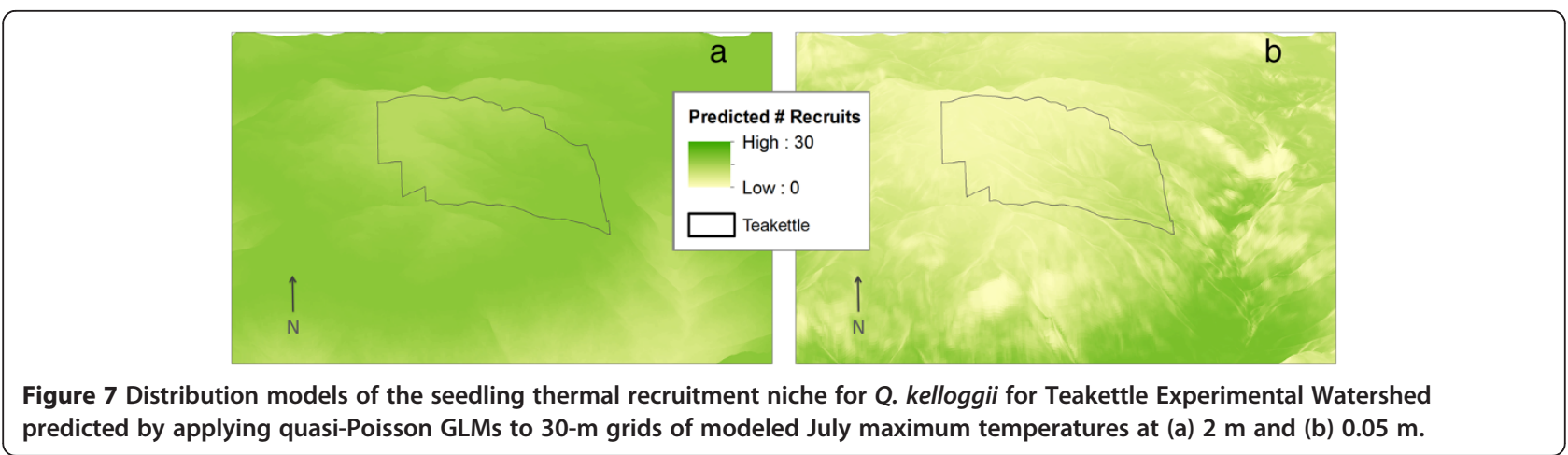


can better explain the heterogeneity found in the recruitment pattern of black oak compared to traditional temperature measurements made at $2 \mathrm{~m}$ above the ground surface.

\author{
Abbreviations \\ DEM: Digital elevation model; GLM: Generalized linear model; \\ MADIS: Meteorological assimilation data ingest system; NOAA: National \\ oceanic and atmospheric administration.
}

\section{Competing interests}

The authors declare that they have no competing interests.

\section{Authors' contributions}

$J D, A F$ and LEF designed the approach to estimating ground-surface temperature; JD and IM implemented and validated the method and analyzed the sensor network data; FWD and LS designed and implemented the common garden experiment and sensor network. LS and JF developed the seedling recruitment models. JD, FWD, LS and IM developed the first draft and all authors contributed to writing the manuscript. All authors read and approved the final manuscript.

\section{Acknowledgements}

We gratefully acknowledge funding support from the National Science Foundation Macrosystems Biology Program, NSF \#EF-1065864, and thank our collaborating investigators (A. Hall, L. Hannah, M. Moritz, M. North, K. Redmond, H. Regan, A. Syphard). The manuscript was improved by comments from H. Regan. S. McKnight and A. Shepard coordinated field site set-up, while E. Conlisk, S. Dashiell, L. di Scipio, E. Hopkins, A. MacDonald, K. Maher, J. McClure, P. Prather, E. Peck, R. Swab, and W. Wilkinson contributed to data collection and maintenance of the common gardens and field sensors. We thank the USDA Forest Service and Tejon Ranch Company for access to field sites. P. Slaughter has been instrumental with development of the field data processing system and database ingest software. Lastly, we would like to thank The Earth Research Institute staff at UC Santa Barbara for their assistance and support.

\section{Author details}

${ }^{1}$ Earth Research Institute, University of California Santa Barbara, Santa Barbara, CA 93106, USA. ².S. Geological Survey, California Water Science Center, Sacramento, CA 95819, USA. ${ }^{3}$ Bren School of Environmental Science \& Management, University of California Santa Barbara, Santa Barbara, CA 93106, USA. ${ }^{4}$ School of Geographical Sciences and Urban Planning, Arizona State University, Tempe, AZ 85287, USA.

Received: 18 April 2013 Accepted: 17 September 2013 Published: 17 October 2013

\section{References}

Ackerly DD, Loarie SR, Cornwell WK, Weiss SB, Hamilton H, Branciforte R, Kraft NJB (2010) The geography of climate change: implications for conservation biogeography. Diversity Distrib 16:476-487

Ashcroft MB (2010) Identifying refugia from climate change. J Biogeogr 37:1407-1413

Ashcroft MB, Gollan JR (2012) Fine-resolution (25 m) topoclimatic grids of nearsurface $(5 \mathrm{~cm})$ extreme temperatures and humidities across various habitats in a large $(200 \times 300 \mathrm{~km})$ and diverse region. Int J Climatol 32:2134-2148

Austin MP (2002) Spatial prediction of species distribution: an interface between ecological theory and statistical modelling. Ecol Model 157:101-118

Bailey TC, Gatrell AC (1995) Interactive spatial data analysis. Longman Scientific \& Technical, Harlow, UK

Bateman BL, VanDerWal J, Johnson CN (2012) Nice weather for bettongs: using weather events, not climate means, in species distribution models. Ecography 35:306-314

Bigg GR, Wise SM, Hanna E, Mansell D, Bryant RG, Howard A (2012) Synoptic climatology of cold air drainage in the Derwent Valley, Peak District, UK. Meteorol Appl. doi:10.1002/met.1317

Boots B, Getis A (1988) Point pattern analysis, vol 07-001. Sage University paper series on quantitative applications in the social sciences. Sage Publications, Beverly Hills
Burns RM, Honkala BH (t c) (1990) Silvics of North America, vol 1, conifers and vol 2, hardwoods. USDA Forest Service Handbook, USDA, Washington DC

Campbell G, Norman J (1998) Introduction to environmental biophysics. Springer Verlag, Berlin

Chen JQ, Saunders SC, Crow TR, Naiman RJ, Brosofske KD, Mroz GD, Brookshire BL, Franklin JF (1999) Microclimate in forest ecosystem and landscape ecology - variations in local climate can be used to monitor and compare the effects of different management regimes. Bioscience 49:288-297

Collins RJ, Carson WP (2004) The effects of environment and life stage on Quercus abundance in the eastern deciduous forest, USA: are sapling densities most responsive to environmental gradients? For Ecol Manage 201:241-258

Daly C, Halbleib M, Smith Jl, Gibson WP, Doggett MK, Taylor GH, Curtis J, Pasteris PP (2008) Physiographically sensitive mapping of climatological temperature and precipitation across the conterminous United States. Int J Climatol 28:2031-2064

Daly C, Conklin D, Unsworth M (2010) Local atmospheric decoupling in complex topography alters climate change impacts. Int J Climatol 30:1857-1864

Davis FW, Sweet LC (2012) From mountain microclimates to the macroecology of tree species distributions in California. Cirmount 6:2-5

Davis MB, Shaw RG (2001) Range shifts and adaptive responses to Quaternary climate change. Science 292:673-679

Dobrowski SZ (2011) A climatic basis for microrefugia: the influence of terrain on climate. Glob Chang Biol 17:1022-1035

Dobrowski SZ, Abatzoglou JT, Greenberg JA, Schladow SG (2009) How much influence does landscape-scale physiography have on air temperature in a mountain environment. Agr Forest Meteorol 149:1751-1758

Flint AL, Childs SW (1987) Calculation of solar-radiation in mountainous terrain. Agr Forest Meteorol 40:233-249

Flint LE, Flint AL (2012) Downscaling future climate scenarios to fine scales for hydrologic and ecological modeling and analysis. Ecol Process 1:1-15

Franklin J (2010) Mapping species distributions: spatial inference and prediction. Cambridge University Press, Cambridge

Franklin J, Davis FW, Ikegami M, Syphard AD, Flint LE, Flint AL, Hannah L (2013) Modeling plant species distributions under future climates: how fine scale do climate projections need to be? Glob Chang Biol 19:473-483

Fridley JD (2009) Downscaling climate over complex terrain: high finescale $(<1000 \mathrm{~m})$ spatial variation of near-ground temperatures in a montane forested landscape (Great Smoky Mountains). J Appl Meteorol Climatol 48:1033-1049

Getis A, Ord JK (1992) The analysis of spatial association by use of distance statistics. Geogr Anal 24:189-206

Gomez-Aparicio L, Perez-Ramos IM, Mendoza I, Matias L, Quero JL, Castro J, Zamora R, Maranon T (2008) Oak seedling survival and growth along resource gradients in Mediterranean forests: implications for regeneration in current and future environmental scenarios. Oikos 117:1683-1699

Griffin JR (1971) Oak regeneration in upper Carmel Valley, California. Ecology 52:862-868

Hijmans RJ, Phillips S, Leathwick J, Elith J (2012) dismo: species distribution modeling. R package version 0.7-17. http://CRAN.R-project.org/ package $=$ dismo

Holtslag AAM, van Ulden AP (1983) A simple scheme for daytime estimates of the surface fluxes from routine weather data. J Clim Appl Meteorol 22:517-529

Ibanez I, Clark JS, LaDeau S, Hille Ris Lambers J (2007) Exploiting temporal variability to understand tree recruitment response to climate change. Ecol Monogr 77:163-177

Jackson ST, Betancourt JL, Booth RK, Gray ST (2009) Ecology and the ratchet of events: climate variability, niche dimensions, and species distributions. Proc Natl Acad Sci USA 106:19685-19692

Kearney M, Porter W (2009) Mechanistic niche modelling: combining physiological and spatial data to predict species' ranges. Ecol Lett 12:334-350

Keppel G, Van Niel KP, Wardell-Johnson GW, Yates CJ, Byrne M, Mucina L, Schut AGT, Hopper SD, Franklin SE (2012) Refugia: identifying and understanding safe havens for biodiversity under climate change. Glob Ecol Biogeogr 21:393-404

Keppel G, Wardell-Johnson GW (2012) Refugia: keys to climate change management. Glob Chang Biol 18:2389-2391

Kolb PF, Robberecht R (1996) High temperature and drought stress effects on survival of Pinus ponderosa seedlings. Tree Physiol 16:665-672

Lenoir J, Gegout J-C, Pierrat J-C, Bontemps J-D, Dhote J-F (2009) Differences between tree species seedling and adult altitudinal distribution in mountain forests during the recent warm period (1986-2006). Ecography 32:765-777 
Lookingbill TR, Urban DL (2003) Spatial estimation of air temperature differences for landscape-scale studies in montane environments. Agr Forest Meteorol 114:141-151

Lundquist JD, Pepin N, Rochford C (2008) Automated algorithm for mapping regions of cold-air pooling in complex terrain. J Geophys Res Atmospheres 113. doi:10.1029/2008JD009879

Ma S, Concilio A, Oakley B, North M, Chen J (2010) Spatial variability in microclimate in a mixed-conifer forest before and after thinning and burning treatments. For Ecol Manage 259:904-915

Mahall BE, Tyler CM, Cole ES, Mata C (2009) A comparative study of oak (Quercus, Fagaceae) seedling physiology during summer drought in southern California. Am J Bot 96:751-761

McDonald PM (1978) Silviculture-ecology of three native California hardwoods on high sites in north central California. Oregon State University, Department of Forest Science, Corvallis, p 309

McLaughlin BC, Zavaleta ES (2012) Predicting species responses to climate change: demography and climate microrefugia in California valley oak (Quercus lobata). Glob Chang Biol 18:2301-2312

North M, Oakley B, Chen J, Erickson H, Gray A, Izzo A, Johnson D, Ma S, Marra J, Meyer M, Purcell K, Rambo T, Roath B, Rizzo D, Schowalter T (2002) Vegetation and ecological characteristics of mixed-conifer and red-fir forests at the Teakettle Experimental Forest. PSW-GTR-186. USDA Forest Service, Albany, CA

Randin CF, Engler R, Normand S, Zappa M, Zimmermann NE, Pearman PB, Vittoz P, Thuiller W, Guisan A (2009) Climate change and plant distribution: local models predict high-elevation persistence. Glob Chang Biol 15:1557-1569

Reyer CPO, Leuzinger S, Rammig A, Wolf A, Bartholomeus RP, Bonfante A, de Lorenzi F, Dury M, Gloning P, Abou Jaoude R, Klein T, Kuster TM, Martins M, Niedrist G, Riccardi M, Wohlfahrt G, de Angelis P, de Dato G, Francois L, Menzel A, Pereira M (2013) A plant's perspective of extremes: terrestrial plant responses to changing climatic variability. Glob Chang Biol 19:75-89

Rosenberg N, Blad B, Verma S (1983) Microclimate: the biological environment. Wiley-Interscience, New York

Standiford R, McDougald N, Phillips R, Nelson A (1991) South Sierra oak regeneration weak in sapling stage. Calif Agr 45:12-14

Stohlgren TJ, Bachand RR, Onami Y, Binkley D (1998) Species-environment relationships and vegetation patterns: effects of spatial scale and tree life-stage. Plant Ecol 135:215-228

Tsujino R, Yumoto T (2007) Spatial distribution patterns of trees at different life stages in a warm temperate forest. J Plant Res 120:687-695

Tyler CM, Kuhn B, Davis FW (2006) Demography and recruitment limitations of three oak species in California. Q Rev Biol 81:127-152

Vanwalleghem T, Meentemeyer RK (2009) Predicting forest microclimate in heterogeneous landscapes. Ecosystems 12:1158-1172

Williams SE, Shoo LP, Isaac JL, Hoffmann AA, Langham G (2008) Towards an integrated framework for assessing the vulnerability of species to climate change. PLoS Biol 6:2621-2626

Zavala MA, Espelta JM, Retana J (2000) Constraints and trade-offs in Mediterranean plant communities: the case of holm oak-Aleppo pine forests. Bot Rev 66:119-149

doi:10.1186/2192-1709-2-30

Cite this article as: Dingman et al:: Cross-scale modeling of surface temperature and tree seedling establishment in mountain landscapes. Ecological Processes 2013 2:30

\section{Submit your manuscript to a SpringerOpen ${ }^{\circ}$ journal and benefit from:}

- Convenient online submission

- Rigorous peer review

- Immediate publication on acceptance

- Open access: articles freely available online

- High visibility within the field

- Retaining the copyright to your article

Submit your next manuscript at $>$ springeropen.com 